\title{
HUBUNGAN PENERAPAN 5 PILAR SANITASI TOTAL BERBASIS MASYARAKAT (STBM) DAN KEJADIAN DIARE DI DESA TAMAN BARU KECAMATAN PENENGAHAN KABUPATEN LAMPUNG SELATAN
}

\author{
Deta Zalva Monica ${ }^{1}$, Mei Ahyanti ${ }^{2 *}$, Nawan Prianto ${ }^{3}$ \\ 1,2,3 Department of Environmental Health, Poltekkes Kemenkes Tanjungkarang
}

\section{Artikel Info :}

Received 8 Agustus 2020

Accepted 20 September 2020

Available online 31 Desember 2020

Editor: Prayudhy Yushananta

Key word :

STBM, ODF, diarrhea, family

Kata Kunci :

STBM, ODF, diare, keluarga

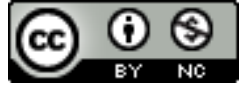

Ruwa Jurai: Jurnal

Kesehatan Lingkungan is licensed

under a Creative Commons

Attribution-NonCommercial 4.0

International License.

\begin{abstract}
A bstract
Diarrhea affects the death of several people around the world. In Lampung Province, the morbidity rate for all age groups tended to increase in 2005-2014. The increase in cases also occurred in South Lampung Regency from 2016-2018, and the most in Taman Baru Village, Penengah District. The study used a cross-sectional design with a sample of 267 households, which are all households in Taman Baru Village. Primary data were collected through a survey using a questionnaire and checklist. The collected data were processed and analyzed in a bivariate manner with the help of a computer program. The results showed a relationship between knowledge and application of the five pillars of STBM and the incidence of diarrhea. Community leaders and village officials fully support STBM activities. The people of Taman Baru Village have not carried out liquid waste management and household waste management, this factor can be the cause of the increasing incidence of diarrhea.
\end{abstract}

Diare berpengaruh terhadap kematian sejumlah orang di seluruh dunia. Di Provinsi Lampung, angka kesakitan pada semua kelompok umur cenderung meningkat tahun 2005-2014. Peningkatan kasus juga terjadi di Kabupaten Lampung Selatan dari tahun 2016-2018, dan terbanyak di Desa Taman Baru Kecamatan Penengahan. Penelitian menggunakan rancangan cross sectional dengan sampel berjumlah 267 KK yang merupakan keseluruhan KK yang ada di Desa Taman Baru. Data primer dikumpulkan melalui survei menggunakan kuesioner dan checklist. Data yang terkumpul diolah dan dianalisa secara bivariat dengan bantuan program komputer. Hasil penelitian menunjukkan ada hubungan antara pengetahuan dan penerapan lima pilar STBM dengan kejadian diare. Tokoh masyarakat dan aparat desa sepenuhnya mendukung kegiatan STBM. Masyarakat Desa Taman Baru belum melakukan pengelolaan limbah cair dan pengelolaan sampah di rumah tangga, faktor ini dapat menjadi penyebab meningkatnya angka kejadian diare.

* Corresponding author: Mei Ahyanti

Jl. Soekarno-Hatta No 6, Bandar Lampung, Provinsi Lampung

Email:meiahyati@poltekkes-tjk.ac.id

\section{PENDAHULUAN}

Sanitasi Total Berbasis Masyarakat yang selanjutnya disebut STBM adalah perilaku higienis dan saniter yang digunakan sebagai acuan dalam penyelenggaraan STBM. STBM memiliki 5 pilar yaitu, berhenti Buang Air Besar Sembarangan (Stop BAB), Cuci Tangan Pakai Sabun (CTPS), Pengelolaan Minuman dan Makanan, Pengamanan Sampah Rumah Tangga,
Pengelolaan Limbah Cair Rumah Tangga (Kementerian Kesehatan RI, 2014).

Ada sekitar 375 juta kasus diare akut di Amerika Serikat setiap tahun $(1,4$ episode perorang per tahun). Di seluruh dunia, penyakit diare berpengaruh terhadap 5 miliar orang per tahun, terhitung hampir 10 juta kematian di negara-negara berkembang. Sebuah laporan tahun 2009 dirilis oleh United Nations Children's dan Organisasi Kesehatan Dunia mengindikasi- 
kan bahwa diare merenggut nyawa sekitar 1,5 juta anak-anak kurang dari 5 tahun setiap tahun (Seupaul, 2019).

Penyakit diare ditandai dengan tinja atau feses berubah lembek atau cair, biasanya terjadi paling sedikit tiga kali dalam 24 jam. Target cakupan pelayanan penderita diare semua umur (SU) yang datang kesarana kesehatan adalah $10 \%$ dari perkiraan jumlah penderita (insiden diare semua umur dikali jumlah penduduk di satu wilayah kerja dalam waktu satu tahun). Tahun 2017 jumlah penderita diare SU yang dilayani di sarana kesehatan sebanyak 4.274.790 penderita dan terjadi peningkatan pada tahun 2018 yaitu menjadi 4.504 .524 penderita atau $62,93 \%$ dari perkiraan diare di sarana kesehatan. Secara nasional Insiden diare pada semua kelompok umur adalah 270/1.000 penduduk (Rapid Survey Diare Tahun 2015). Terjadi 10 kali KLB Diare pada tahun 2018 yang tersebar di 8 provinsi, 8 kabupaten/kota. Kabupaten Tabanan dan Kabupaten buru masing-masing terjadi 2 KLB. Jumlah penderita 756 orang dan kematian 36 orang (CFR 4,76\%) (Kemenkes RI, 2018).

Terdapat kecenderungan peningkatan Insidens Rate diare untuk semua kelompok umur di Provinsi Lampung dari tahun 2005 - 2014, yaitu dari 9,8 per 1000 penduduk menjadi 21,4 per 1000 penduduk tahun 2013. Peningkatan kasus diare juga terjadi di wilayah Kabupaten Lampung Selatan dari tahun 2016 - 2018 (Dinas Kesehatan Kabupaten Lampung Selatan, 2017). Distribusi kasus per wilayah kerja Puskesmas yang ada di Kabupaten Lampung Selatan kasus diare terbanyak yaitu di Puskesmas Rawat Inap Penengahan Kecamatan Penengahan. Penyakit diare dipengaruhi oleh kondisi sanitasi yang kurang. Program STBM telah dicanangkan oleh pemerintah namun kejadian diare semakin meningkat, maka tujuan dari penelitian ini adalah mengkaji penerapan 5 pilar STBM dan kejadian diare.

\section{METODE}

Penelitian menggunakan rancangan Cross sectional. Populasi penelitian ini adalah seluruh KK di desa Taman Baru Kecamatan Penengahan Kabupaten Lampung Selatan berjumlah 267 KK. Sampel adalah total populasi yaitu 267 KK. Sebagai responden adalah kepala keluarga atau anggota keluarga yang dapat memberikan informasi terkait variabel penelitian. Pengumpulan data dilakukan pada bulan Maret sampai April 2020. Data primer tentang kejadian diare, pengetahuan, dukungan tokoh masyarakat, pemaparan petugas kesehatan dan penerapan pilar STBM dikumpulkan melalui wawancara menggunakan kuesioner dan pengamatan menggunakan checklist. Selanjut-nya data yang telah terkumpul dianalisa secara univariat dan bivariate dengan uji chi square dan disajikan dalam bentuk tabel.

\section{HASIL}

Penerapan 5 Pilar STBM digambarkan pada tabel 1. Hasil penelitian mendapatkan frekuensi buang air besar sembarangan sebesar 37.1\%, tidak melakukan cuci tangan pakai sabun sebanyak 19.9\%, seluruh responden telah melakukan pengelolaan makanan dan minuman dengan aman (100\%), terdapat $93,6 \%$ responden dengan pengelolaan sampah rumah tangga yang tidak baik, dan pengelolaan limbah cair rumah tangga yang tidak baik sebesar $86.9 \%$.

Tabel 2 menyajikan hasil analisis secara bivariat untuk melihat hubungan antara dua variabel. Dari hasil analisis dapat dijelaskan ada hubungan yang bermakna antara perilaku $B A B$ $(p=0,000)$, perilaku cuci tangan $(p=0,001)$ dan pengelolaan limbah rumah tangga $(p=0,004)$ dengan kejadian diare. Sedangkan variabel yang tidak berhubungan secara bermakna adalah pengelolaan sampah rumah tangga ( $p=0,087$ ). Analisis secara bivariat tidak dapat dilakukan terhadap variabel pengelolaan makanan, disebabkan $100 \%$ responden telah melakukan pengolahan makanan dan minuman yang aman di tingkat rumah tangga.

Dari lima pilar kemudian digabungkan menjadi variabel penerapan STBM. Hasil analisis mendapatkan $p$ value $=0,000$, maka dapat dinyatakan terdapat hubungan yang bermakna antara penerapan STBM dengan kejadian diare.

\section{PEMBAHASAN}

\section{Perilaku Buang Air Besar}

Desa Taman Baru sedang dalam proses Open Deffecation Free (ODF) pada tahun 2020. Dari wawancara yang dilakukan, sebagian responden yang mengatakan masih berperilaku BABS yaitu di sungai dan di kebun atau dijamban cemplung 
yang dibuat di belakang rumah, dan beberapa rumah disana mempunyai jamban tetapi saluran penampungan tinja atau septictanknya langsung ke sungai, setiap keluarga harus memiliki jamban sehat karena perilaku $B A B$ di sungai dan kebun dapat menyebabkan penyakit karena kotoran/ tinja merupakan tempat perkembang-biakan kuman salah satunya adalah kuman penyebab diare. Menggunakan jamban tanpa septictank, tinja dapat merembes kedalam tanah sekitar jamban dan mencemari sumber air. Stop BABS adalah suatu kondisi dimana setiap orang dalam suatu kelompok masyarakat sudah melakukan perilaku buang air besar pada tempatnya, sehingga tidak berpotensi menyebarkan penyakit (Yushananta, Ahyanti, \& Hasan, 2018). Penggunaan toilet yang tidak sehat dan pembuangan yang tidak aman tinja berkontribusi terhadap penyebaran diare (Pahmi, 2019).

Tabel 1. Distribusi Responden Berdaraskan 5 Pilar Sanitasi Total Berbasis Masyarakat

\begin{tabular}{lll}
\hline Sanitasi Total Berbasis Masyarakat & Frekuensi & Persentase \\
\hline Buang Air Besar Sembarangan & & \\
BABS & 168 & 62.9 \\
Tidak BABS & 99 & 37.1 \\
Cuci Tangan Pakai Sabun & & \\
Tidak CTPS & 53 & 19.9 \\
CTPS & 214 & 80.1 \\
Pengelolaan Makanan dan Minuman & & \\
Tidak Aman & 0 & 0 \\
Aman & 267 & 100 \\
Pengamanan Sampah Rumah Tangga & & \\
Tidak Aman & 250 & 93.6 \\
Aman & 17 & 6.4 \\
Pengamanan Limbah Cair Rumah Tangga & & \\
Tidak Aman & 232 & 86.9 \\
Aman & 35 & \\
\hline
\end{tabular}

Hasil penelitian ini sejalan dengan penelitianpenelitian lain yang menyatakan terdapat hubungan bermakna antara BABS dengan kejadian diare (Entianopa et al., 2017; Mukti et al., 2016; Prayitno \& Widati, 2018; Syam \& Asriani, 2019). Dalam Permenkes RI no. 3 tahun 2018 disebutkan bahwa buang air besar di jamban yang sehat sangat efektif untuk memutus mata rantai penularan diare. Pembangunan jamban sehat harus diupayakan, sehingga keluarga miliki akses terhadap jamban, serta digunakan oleh keluarga. Jamban dapat ditempatkan di dalam rumah atau di luar rumah agar mudah dijangkau oleh penghuni rumah. Syarat standar yang harus dimiliki jamban agar menjamin kesehatan bangunan jamban antara lain : memiliki atap, fungsinya agar pemakai terlindung dari gangguan cuaca dan gangguan lainnya. Terdapat lubang pembuangan kotoran dengan konstruksi leher angsa atau bukan leher angsa berpenutup dengan lantai jamban kedap air, tidak licin, dan dilengkapi SPAL pada bangunan tengah jamban, dan pada bangunan bawah jamban, terdapat bak penampungan (septictank) fungsinya sebagai pengolah dan pengurai kotoran/tinja agar pencemaran atau kontaminasi dari tinja melalui vektor pembawa penyakit, baik secara langsung maupun tidak langsung dapat dicegah.

\section{Perilaku cuci tangan pakai sabun}

Budaya cuci tangan dengan sabun terutama sebelum makan dan setelah BAB merupakan sarana penghindar penyakit diare. Tangan yang tidak dibersihkan dengan benar, mengandung kuman penyakit dan menjadi media masuknya penyakit kedalam tubuh manusia (Nugraheni, 2012).

Penelitian ini menunjukkan bahwa ada hubungan antara penerapan cuci tangan pakai sabun dengan kejadian diare. Hasil observasi diketahui bahwa pada rumah responden sudah tersedia air mengalir di dalam rumah untuk mencuci tangan, tersedia sabun untuk mencuci tangan di dalam rumah, namun perlengkapan khusus CTPS di dalam rumah, dan waktu cuci tangan bagi keluarga masih kurang tepat. Waktu-waktu penting CTPS adalah sebelum dan 
sesudah makan, sesudah buang air besar, sesudah menceboki dan membuang tinja, dan sebelum menyajikan makanan. Mencuci tangan dengan sabun, terutama sesudah buang air besar, sesudah membuang tinja anak, sebelum menyiapkan makanan, sebelum menyuapi makan anak dan sebelum makan, mempunyai dampak dalam kejadian diare (menurunkan angka kejadian diare sebesar 47\%) (Djarkoni, Lampus, Siagian, Kaunang, \& Palandeng, 2014; Kody \& Landi, 2016; Risnawaty, 2017; Yushananta \& Usman, 2018).

Tabel 2. Hubungan 5 Pilar STBM Dengan Kejadian Diare

\begin{tabular}{|c|c|c|c|c|c|c|c|c|}
\hline \multirow[t]{2}{*}{ BABS } & \multicolumn{3}{|c|}{ Diare } & \multicolumn{2}{|c|}{ Tidak Diare } & \multirow{2}{*}{$\mathrm{N}$} & \multirow{2}{*}{$\%$} & \\
\hline & $\mathrm{N}$ & $\%$ & & $\mathrm{~N}$ & $\%$ & & & \\
\hline \multicolumn{9}{|l|}{ Perilaku BAB } \\
\hline BABS & 52 & 31 & 116 & & 69 & 168 & 100 & \multirow{2}{*}{0.000} \\
\hline Tidak BABS & 60 & 60,6 & 39 & & 39,4 & 99 & 100 & \\
\hline \multicolumn{9}{|l|}{ Perilaku CTPS } \\
\hline Tidak CTPS & 33 & 62,3 & 20 & & 37,7 & 53 & 100 & \multirow{2}{*}{0.001} \\
\hline CTPS & 79 & 36,9 & 135 & & 63,1 & 214 & 100 & \\
\hline \multicolumn{9}{|c|}{ Pengelolaan Sampah Rumah Tangga } \\
\hline Tidak aman & 101 & 40,4 & 149 & & 59,6 & 250 & 100 & \multirow{2}{*}{0.087} \\
\hline Aman & 11 & 64,7 & 6 & & 35,3 & 17 & 100 & \\
\hline \multicolumn{9}{|c|}{ Pengelolaan Limbah Rumah Tangga } \\
\hline Tidak aman & 89 & 38,4 & 143 & & 61,6 & 232 & 100 & \multirow{2}{*}{0.004} \\
\hline Aman & 23 & 65,7 & 12 & & 34,3 & 35 & 100 & \\
\hline \multicolumn{9}{|c|}{ Sanitasi Total Berbasis Masyarakat } \\
\hline Tidak diterapkan & 59 & 56,7 & 45 & & 43,3 & 104 & 100 & \multirow{2}{*}{0.000} \\
\hline Diterapkan & 53 & 32,5 & 110 & & 67,5 & 163 & 100 & \\
\hline
\end{tabular}

Mencuci tangan dengan baik dan benar hendaknya menggunakan sabun. Sabun akan membunuh mikroorganisme merugikan bagi tubuh. Cuci tangan saja tidak cukup karena air mengalir tidak membunuh bakteri yang terdapat pada tangan. Sabun mengandung zat desinfektan seperti TCC dan triclosan. Zat ini lebih efektif membunuh kuman dibandingkan hanya mengandalkan aliran air dan gesekan saat mencuci tangan dalam membasmi kuman. Maka diharapkan untuk mempunyai tempat cuci tangan yang tersedia air mengalir dan sabun. Serta cuci tangan pakai sabun yang baik selama 20-30 detik setiap waktu-waktu penting, untuk menurangi tingkat penyakit dan terhindar dari kuman penyakit (Kody \& Landi, 2016; Purwandari, Ardiana, \& Wantiyah, 2013; Utomo, 2013).

\section{Pengelolaan Makanan dan Minuman di rumah tangga}

Penyakit yang menyerang manusia dapat disebarkan melalui air sehingga trjadi penyebarab wabah. Seluruh responden telah melakukan pengelolaan makanan dan minumannya dengan baik atu pada kriteria aman (100\%). Pengelolaan makanan dan minuman dengan baik yaitu menggunakan air minum/air yang dimasak sebelum dikonsumsi, menggunakan air minum yang sudah diolah ditempatkan di wadah yang tertutup rapat, Secara rutin membersihkan wadah air minum (setidaknya seminggu sekali), menyimpan makanan yang sudah dimasak dalam wadah tertutup dan bersih, dan selalu mencuci bahan makanan sebelum diolah dengan air yang mengalir dan bersih. Sehingga kemungkinan vektor lalat atau vektor lain untuk hinggap di makanan cukup kecil.

Pengelolaan air minum rumah tangga yang efektif yaitu pengelolaan air baku, pengelolaan air untuk minum, wadah penyimpanan air minum, dan hal penting dalam pengelolaan air minum makanan rumah tangga (PAMM-RT). Pengelolaan makanan rumah tangga yang efektif mengikuti 6 prinsip hygiene sanitasi makanan yaitu, pemilihan bahan makanan, penyimpanan bahan makanan, pengolahan makanan, penyimpanan makanan matang, pengangkutan makanan, dan penyajian makanan. Apabila 6 prinsip pengelolaan makanan minuman diterapkan dirumah tangga, dapat mencegah terjadinya penyakit diare (Ikrimah, Maharso, \& Noraida, 2019; Rostina \& Mutiana, 2018). 
4. Pengelolaan sampah rumah tangga

Penelitian ini menunjukkan bahwa tidak ada hubungan antara pengelolaan sampah rumah tangga dengan kejadian diare. Hasil ini dapat disebabkan oleh sebagaian besar rumah tangga tidak melakukan pengelolaan sambah dengan baik. Sampah padat rumah tangga dibuang berserakan dihalaman rumah, tempat sampah dirumah tidak terpisah antara sampah organik dan anorganik, sampah yang terkumpul dirumah tidak diangkut ke tempat pembuangan akhir secara rutin karena masih dalam proses pembuatan lahan TPA maka sampah masih dibakar dihalaman rumah atau dibuang disungai, dan sampah padat rumah tangga tidak dikelolah dengan didaur ulang atau dijadikan pupuk.

Pengelolaan sampah rumah tangga yang aman meliputi proses pengumpulan sampah menggunakan wadah yang tertutup, pengangkutan dari dalam rumah ke tempat pengumpulan sementara yang ada di luar rumah, untuk sampah organic dapat dilakukan proses pengomposan (dibuat lubang di pekarangan rumah untuk menimbun sampah organic), melakukan daur ulang untuk sampah anorganik atau pembuangan dari material sampah dengan cara yang tidak membahayakan kesehatan masyarakat. Supaya rumah aman dari gangguan sampah, maka sebaiknya sampah tidak berada di dalam rumah dan harus dibuang setiap hari, pemilahan dalam bentuk pengelompokkan dan pemisahan sampah sesuai dengan jenis, jumlah, dan/atau sifat sampah, pemilahan sampah dilakukan terhadap 2 (dua) jenis sampah, yaitu organik dan anorganik. Untuk itu perlu disediakan tempat sampah tersebut. Tempat sampah harus tertutup rapat, sampah diambil dan dikumpulkan kemudian dipindahkan dari rumah ke tempat penampungan sementara atau tempat pengolahan sampah terpadu, sampah yang telah dikumpulkan di tempat penampungan sementara atau tempat pengolahan sampah terpadu diangkut ke tempat pemrosesan akhir. Prinsip pengamanan sampah rumah tangga yaitu reduce adalah mengurangi sampah dengan mengurangi pemakaian barang atau benda yang tidak terlalu dibutuhkan, reuse adalah memanfaatkan barang yang sudah tidak terpakai tanpa mengubah bentuk, dan recycle adalah mendaur ulang kembali barang lama menjadi barang baru.

\section{Pengelolaan limbah cair rumah tangga}

Limbah cair rumah tangga berupa air bekas yang dihasilkan dari buangan dapur, kamar mandi, dan sarana cuci tangan harus disalurkan ke saluran pembuangan air limbah. Tidak adanya saluran air limbah atau jenis saluran yang digunakan terbuka, akan menyebabkan air limbah merembes ke tanah yang dilaluinya dan menyebabkan pencemaran. Air limbah juga dapat mencemari jika ada sumber air bersih disekitar air limbah. Jenis penampungan air limbah sebaiknya adalah sumur serapan atau selokan umum, penampungan air limbah di pekarangan, kebun, atau sawah juga dapat mencemari tanah dan mengundang binatang seperti lalat. Air limbah yang mengandung kuman diare dapat masuk ke air bersih ataupun makanan.

Berdasarkan observasi hampir seluruh responden masuk kedalam kriteria tidak aman dalam hal pengelolaan limbah cair rumah tangga. Limbah cair tidak diolah dan langsung dibuang ke sungai, air limbah dari kamar mandi dan dapur tercampur dengan air jamban. Pada tingkat rumah tangga diperlukan sarana berupa sumur resapan dan saluran pembuangan air limbah rumah tangga. Limbah cair rumah tangga yang berupa tinja dan urine disalurkan ke tangki septic yang dilengkapi dengan sumur resapan agar tidak mengundang vektor seperti lalat. Air limbah yang mengandung kuman diare dapat masuk ke air bersih ataupun makanan

Menurut Langit (2016) berdasarkan hasil penelitian tidak adanya saluran air limbah atau jenis saluran yang digunakan terbuka, akan dapat menyebabkan air limbah merembes ke tanah - tanah yang dilaluinya dan menyebabkan pencemaran. Air limbah juga dapat mencemari jika ada sumber air bersih di sekitar air limbah. Jenis penampung air limbah sebaiknya adalah sumur resapan atau selokan umum (Langit, 2016).

\section{Penerapan 5 pilar STBM}

STBM merupakan sebuah pendekatan dalam mengarahkan perilaku masyarakat kearah yang lebih baik yaitu perilaku yang higienis dan saniter melalui upaya pemberdayaan dengan 
memicu masyarakat. Upaya telah dilakukan oleh pemerintah dalam melakukan pendekatan tersebut. Akan tetapi praktiknya di masyarakat kadang kala tidak sesuai harapan. Hal ini dibuktikan dengan hasil penelitian ini, terdapat hubungan yang bermakna antara penerapan STBM dengan kejadian diare.

Hasil analisa STBM melalui 5 pilar menyimpulkan bahwa terdapat hubungan yang bermakna antara penerapan STBM dengan kejadian diare. 5 pilar harus dilaksanakan dengan benar dan secara bersama-sama antara masyarakat, petugas kesehatan, tokoh masyarakat dan aparat desa agar kajadian diare dapat dikendalikan.

\section{SIMPULAN}

Terdapat hubungan yang bermakna antara pengetahuan dan penerapan STBM dengan kejadian diare di Desa Taman Baru Kecamatan Penengahan Kabupaten Lampung Selatan. Untuk mengendalikan kejadian diare, perlu dilaksanakan peningkatan pengetahuan melalui penyuluhan dan penerapan STBM secara benar dan bersama-sama antara masyarakat, petugas kesehatan, tokoh masyarakat dan aparat desa.

\section{DAFTAR PUSTAKA}

Dinas Kesehatan Kabupaten Lampung Selatan. (2017). Profil Kesehatan Kabupaten Lampung Selatan. Kalianda: Dinas Kesehatan Kabupaten Lampung Selatan.

Djarkoni, I. H., Lampus, B. ., Siagian, I. E., Kaunang, W. P. ., \& Palandeng, H. (2014). Hubungan Perilaku Cuci Tangan Pakai Sabun Dengan Kejadian Diare Di Sd Advent Sario Kota Manado. Jurnal Kedokteran Komunitas Dan Tropik, 2(3), 95-98.

Entianopa, M., Marisdayana, R., Andriani, L., \& Hendriani, V. (2017a). Analisis Pelaksanaan Program STBM Pilar Pertama Stob Buang Air Besar Sembarangan di Desa Ampelu Kabupaten Batanghari. Jurnal Kesehatan Terpadu, Vol. 1. https://doi.org/10.36002/jkt.v1i2.267

Entianopa, M., Marisdayana, R., Andriani, L., \& Hendriani, V. (2017b). Analisis Pelaksanaan Program Stbm Pilar Pertama Stop Buang Air Besar Sembarangan Di Desa Ampelu Kabupaten Batanghari. Jurnal Kesehatan Terpadu, 1(2), 4953. https://doi.org/10.36002/jkt.v1i2.267

Ikrimah, I., Maharso, M., \& Noraida, N. (2019). Hubungan Pengelolaan Air Minum dan
Makanan Rumah Tangga Dengan Kejadian Diare. JURNAL KESEHATAN LINGKUNGAN: Jurnal Dan Aplikasi Teknik Kesehatan Lingkungan, 15(2), 655.

https://doi.org/10.31964/jkl.v15i2.134

Kemenkes RI. (2018). Profil Kesehatan Indonesia Tahun 2018.

https://doi.org/https://doi.org/10.1002/qj

Kementerian Kesehatan RI. (2014). Peraturan Menteri Kesehatan RI No. 03 Tahun 2014 tentang Sanitasi Total Berbasis MAsyarakat.

Kody, M. M., \& Landi, M. (2016). Kebiasaan Mencuci Tangan dengan Kejadian Diare pada Anak Sekolah Dasar Negeri Kota Waingapu Kabupaten Sumba Timur. Jurnal Kesehatan Primer, 1(1), 47-55.

Langit, L. S. (2016). Hubungan Kondisi Saitasi Dasar Rumah dengan Kejadian Diare pada Baita di Wilayah Kerja Puskesmas Rembang 2. Jurnal Kesehatan Masyarakat (e-Journal), 4(2), 160165.

Mukti, D., Raharjo, M., \& Dewanti, N. (2016). Hubungan Antara Penerapan Program Sanitasi Total Berbasis Masyarakat (Stbm) Dengan Kejadian Diare Di Wilayah Kerja Puskesmas Jatibogor Kabupaten Tegal. Jurnal Kesehatan Masyarakat Universitas Diponegoro, 4(3), 767775.

Nugraheni, D. (2012). Hubungan Kondisi Fasilitas Sanitasi Dasar Dan Personal Hygiene Dengan Kejadian Diare Di Kecamatan Semarang Utara Kota Semarang. Jurnal Kesehatan Masyarakat.

Pahmi, L. (2019). Household Risk Factors For Diarrhoea Disease In Children Under Five Years Old In Indonesia. Jurnal Ilmu Kesehatan Masyarakat, 10(March), 50-58.

Prayitno, J., \& Widati, S. (2018). Kajian Strategi Promosi Kesehatan Sanitasi Total. Jurnal Kesehatan Lingkungan, 11(3), 267-274.

Purwandari, R., Ardiana, A., \& Wantiyah. (2013). Hubungan antara Perilaku Mencuci Tangan rengan Insiden Diare pada Anak Usia Sekolah

77 Kabupaten Jember. Jurnal Keperawatan, 4(2), 122-130.

Risnawaty, G. (2017). Faktor Determinan Perilaku Cuci Tangan Pakai Sabun (Ctps) Pada Masyarakat Di Tanah Kalikedinding. Jurnal PROMKES, 4(1), 70. https://doi.org/10.20473/jpk.v4.i1.2016.70-81

Rostina, \& Mutiana, R. (2018). Hubungan Perilaku Penjamah Maknan dengan Keberadaan MPN Coliform pada Minuman di Angkringan Kabupaten Barru. Jurnal Sololipu: Media Komunikasi Sivitas Akademica Dan Masyarakat, 
18(2), S-102.

Seupaul, R. A. (2019). Diarrhea Red flags Anatomic essentials.

Syam, S., \& Asriani, A. (2019). Penerapan Sanitasi Total Berbasis Masyarakat (Stbm) Pilar 1 Stop Buang Air Besar Sembarangan (Stop Babs) Dengan Kejadian Penyakit Diare Di Kelurahan Lakkang Kecamatan Tallo Kota Makassar. Sulolipu: Media Komunikasi Sivitas Akademika Dan Masyarakat, 19(1), 109. https://doi.org/10.32382/sulolipu.v19i1.1035 Utomo, A. M. dkk. (2013). Hubungan Perilaku Cuci Tangan Pakai Sabun (CTPS) Dengan Kejadian Diare Anak Usia Sekolah Di Sdn 02 Pelemsengir
Kecamatan Todanan Kabupaten Blora. Jurnal Keperawatan, 6(1), 1-10. https://doi.org/10.1007/s11340-009-9279-9 Yushananta, P., Ahyanti, M., \& Hasan, A. (2018). Sanitasi Total Berbasis Masyarakat di Desa Muara Putih Kecamatan Natar Kabupaten Pesawaran. Sakai Sambayan Jurnal Pengabdian Kepada Masyarakat, 2(2), 76. https://doi.org/10.23960/jss.v2i2.79 Yushananta, P., \& Usman, S. (2018). The Incidence of Diarrhea in Babies Affected through the Cleanliness of Eating Utensils and Hands. Journal of Medical Science And Clinical Research, 6(9). https://doi.org/10.18535/jmscr/v6i9.137 